\title{
GCU
}

Glasgow Caledonian

University

University for the Common Good

\section{Providing ecosystem services in a challenging environment by dealing with bundles, trade-offs, and synergies}

Gonzalez-Ollauri, Alejandro; Mickovski, Slobodan B.

Published in:

Ecosystem Services

DOI:

10.1016/j.ecoser.2017.10.004

Publication date:

2017

Document Version

Author accepted manuscript

Link to publication in ResearchOnline

Citation for published version (Harvard):

Gonzalez-Ollauri, A \& Mickovski, SB 2017, 'Providing ecosystem services in a challenging environment by dealing with bundles, trade-offs, and synergies', Ecosystem Services, vol. 28, no. Part C, pp. 261-263. https://doi.org/10.1016/j.ecoser.2017.10.004

\section{General rights}

Copyright and moral rights for the publications made accessible in the public portal are retained by the authors and/or other copyright owners and it is a condition of accessing publications that users recognise and abide by the legal requirements associated with these rights.

Take down policy

If you believe that this document breaches copyright please view our takedown policy at https://edshare.gcu.ac.uk/id/eprint/5179 for details of how to contact us. 
Providing ecosystem services in a challenging environment by dealing with bundles, trade-offs, and synergies

Alejandro Gonzalez-Ollauri ${ }^{1,2}$ and Slobodan B. Mickovski ${ }^{1}$

${ }^{1}$ BEAM Research Centre, Glasgow Caledonian University, Cowcaddens Road G4 0BA Glasgow UK

${ }^{2}$ Corresponding author: alejandro.ollauri@gcu.ac.uk ; Gollauri@gmail.com

\begin{abstract}
The provision of ecosystem services (ES) relies upon the adequate functioning of multifunctional ecosystems and landscapes. Multifunctional ecosystems are prone to the emergence of ES bundles, trade-offs, and synergies due to various ecological and socio-ecological drivers. Dealing effectively with ES bundles, in general, and the interactions between ES, in particular, is crucial to achieve high degrees of sustainability and resilience by human societies. Yet, ES associations and interactions are difficult to assess, posing important challenges to ecologists, decision-makers, environmental planners, and managers. For this Special Section, we selected eight original contributions that were presented during the $5^{\text {th }}$ International EcoSummit held in Montpellier (France) in the summer of 2016. Together, the studies presented herein, cover novel research, tools, and approaches focusing on overcoming the multiple challenges associated with the quantification and analysis of ES bundles, trade-offs, and synergies. These will certainly contribute to develop a better understanding and more comprehensive studies focusing on ES interactions within multifunctional ecosystems in the future.
\end{abstract}

\title{
1. Introduction
}

Ecosystem services, the benefits that humans get from ecosystems, are increasingly becoming a central piece within environmental management strategies and policies seeking sustainability (Daw et al., 2010; de Groot et al., 2010). The provision of ecosystem services (ES) relies upon the complexity and adequate functioning of ecosystems and landscapes (Mouchet et al., 2017). In fact, as the body of knowledge in ES is developing, experts are stressing the role of regulating services (e.g. carbon sequestration and storage, erosion prevention, pollination, etc.) in the sustainable provision of other ES categories (e.g. provisioning and cultural) (Bennett et al., 2009). One example of this is the emerging science of soil- and water-bioengineering where regulating services such as landslide mitigation and erosion protection using vegetation are providing for recreational greenscapes and foster natural heritage on top of enhancements in carbon sequestration and biodiversity (e.g. Gonzalez-Ollauri and Mickovski 2017). Yet, governments, enterprises, and the society at large tend to see ecosystems, or landscapes, as mere providers of a single, or just a few tangible goods (e.g. fiber, fuel, food, timber, etc.). Consequently, it is neglected that the supply of ES is the fruit from the regulating and multifunctional capacity of landscapes, and the interaction between their biotic and abiotic components.

Ecosystem multifunctionality is a fundamental and challenging concept in ecology (Thompson and Gonzalez, 2016). It has become relevant to environmental managers after acknowledging that ESs tend to appear in the landscape as "bundles" - i.e. a given landscape unit 
provides multiple ES at a given location and time (e.g. Raudsepp-Hearne et al., 2010; Mouchet et al., 2014). Furthermore, when ES are subject to interactions between themselves, as a result of natural processes (i.e. ecological drivers) or management decisions (i.e. socio-ecological drivers), "trade-offs" and "synergies" may emerge (Bennet et al., 2014). In simple terms, a trade-off between ES is characterised by the decrease in provisioning of one or several ES as a result of increasing the supply or flow of one ecosystem service (Turkelboom et al., 2016). Most ES trade-offs occur due to purposefully increasing provisioning services (Bennett et al., 2009). A synergy, however, is a win-win situation in which the provision of a particular ecosystem service enhances the servicing capacity of other ES (Howe et al., 2014).

Ecosystem service bundles, in general, and the interactions between ES, in particular, are difficult to assess, posing important challenges to ecologists, decision-makers, environmental planners, and managers (Deng et al., 2016). As a result, much effort is being allocated into understanding the socio-ecological conditions and the ecosystem dynamics behind the occurrence of ES bundles, the interaction between ES, and the direction of these. Further difficulties to quantify ES bundles, tradeoffs, and synergies are related to the transient and dynamic nature of ecosystems (e.g. Koch et al., 2009; Hein et al., 2016). Ecosystems are not static entities, and they evolve over time (e.g. due to climate change, land use change, etc.), leading to changes in the array of ES provided by a given ecosystem at a given location or time (Koch et al., 2009; Mouchet et al., 2014; Hein et al., 2016). Additionally, population growth combined with shifts in consumption patterns in some human societies (e.g. China) is exerting a pressing demand for ES without precedents (CCICED, 2010). Last but not least, ES bundles, trade-offs, and synergies also arise from the interaction between stakeholders (Howe et al., 2014), which tends to split the key actors into winners and losers (Daw et al., 2010), and can create social conflicts at multiple spatial or even temporal scales (Mouchet et al., 2014). Effective tools and approaches are thus needed to deal with all the challenges indicated above, and to define sustainable strategies and management plans ensuring that ecosystems meet the present and future demands for ES.

This Special Section, named "Providing ecosystem services in a challenging environment by dealing with bundles, trade-offs, and synergies" comprises a selection of eight original contributions that were presented during the $5^{\text {th }}$ International EcoSummit held in Montpellier (France) in the summer of 2016. Together, the studies cover novel research, tools, and approaches focusing on overcoming the multiple challenges associated to ES bundles, trade-offs, and synergies. The goal is not to cover all the challenges mentioned above, as we acknowledge that the task is nontrivial, but to give the reader a taste of how scientists are currently approaching the issue with the hope to inspire future work aiming at optimising the supply of ecosystem services in a changing and challenging environment.

In the first paper, Cord and collaborators present a review of the main concepts, methods, and areas requiring further research for the systematic analysis of ES trade-offs and synergies. Through multidisciplinary meetings and discussions, the authors of the first constribution identified four main objectives that need addressing: (i) the identification and characterisation of ES bundles in the landscape; (ii) the identification of drivers that shape ES interactions; (iii) the evaluation of biophysical constraints limiting the multifunctionality of landscapes; and (iv) the effect of environmental planning, 
management, and policy decisions on ES relationships. These four objectives are further covered in the following papers of the Special Section.

The second paper presents a blueprint for mapping and analysing ES bundles at the national scale. In this paper, Dittrich and collaborators present the most comprehensive analysis to date of ecosystem services and their relation to socio-environmental variables in Germany. To do so, the authors synthesised spatial indicators for eleven ecosystem services followed by the implementation of the "Self-Organising-Maps" method (Kohonen, 1998) to define and map bundles. Subsequently, they collated data from eighteen spatial covariates to delineate socio-environmental clusters which were, then, overlapped on ecosystem bundles maps. The approach from Dittrich and collaborators offers a great potential for future development as it permits identification of areas with more multifunctional use of the landscape, or successful detection of trade-offs and synergistic relationships.

In the third paper, Fernandez-Campo and collaborators look into how the use of one key ecosystem service (i.e. bioenergy production) changes the provision of other ES in the context of two Norwegian municipalities dependent on forest ecosystems. The key aspect of this contribution, however, is that it explores how using different spatial generalisation scales to portray ES bundles can change the perception of ES provision. The authors did so by implementing a "moving window algorithm" (Dillard, 1967) on ES bundles maps. As the authors stress, selecting an appropriate scale to depict ES on maps is of the utmost importance to detect mismatches in supply, demand, and management of ES (Norton et al., 2016).

Poor management strategies and decisions can be a major driver for conflicts between ES (Bennett et al., 2009), as pointed out before. However, managing the conditions that lead to trade-offs, and managing the trade-offs per se, could also be part of the solution to mitigate negative interactions among ES, and set the basis for win-win, or synergistic, situations (Howe et al., 2014). In this context, in the fourth paper of this Special Section, Pohjanmies and collaborators present a framework to evaluate conflicts between ES and to find optimum management solutions that maximize the provision of two conflicting ES. Focusing on production forests in Finland, the authors aim to resolve the conflicts emerging between provisioning services (i.e. timber production), usually the most conflicting ones (Bennett et al., 2009), and other services by exploring the impact of diversifying forest management regimes.

Conflicting drivers that trigger ES trade-offs are not only ecological, such as landscape biophysical constraints - i.e. the natural capacity of landscape to satisfy the demand for and flow of multiple ES, or such as interactions between clashing ES in the natural environment -e.g. more timber extraction, less carbon storage. Drivers leading to ES trade-offs are in many instances sociologicalecological, too as indicated before (Mouchet et al., 2014), By definition, ecosystem products and processes would not be services without a society that uses them (see Braat \& De Groot, 2012). Multiple and diverse stakeholders may have different interests and perceptions over a set of ES. In some cases, stakeholders belong to different spatial (e.g. local or global) or even to different time scales (e.g. present with respect to future generations) (Bennett et al., 2009), making the issue even more challenging. Acknowledging the array of perceptions and interests among stakeholders on a given ES bundle could point out potential socio-ecological conflicts, permitting implementation of specific 
management measures to bypass conflict and create compromise. In this setting, Mathe and collaborators illustrate the potential of the so-called "Rapid Ecosystem Services Participatory Appraisal (RESPA)" (Werner et al., 2014) to rank ES collectively in the light of stakeholders' perceptions. The authors of the fifth paper take the reader on a journey through the six RESPA steps, which, among other things, ensure that the motives behind perceptions are clearly identified, and that the stakeholders' views are effectively transmitted to decision makers. This approach could be applied in specific ES disciplines such as eco-engineering (e.g. www.ecomedbio.eu) where a new dynamics between academia and industry can be fostered.

Further to the consideration of socio-ecological drivers leading to the emergence of ES conflicts, in the sixth paper, Berbes-Blazquez and collaborators illustrate how access to features related to the supply of a dominant provisioning service (i.e. plantain) may regulate the well-being of resourcedependent societies. By comparing two farming production systems within an indigenous county in Costa Rica, the authors stress how access to land, technology, knowledge, markets, capital, and labour may derive into serious conflicts at the community level (e.g. power gain by outsiders ). These conflicts will certainly shape how the community profits from the local ecosystem and, thus might encourage the emergence of further trade-offs. Yet, according to the authors, ES access analyses could inform management strategies, as they: (i) identify how power is distributed among stakeholders; (ii) permit to understand the logic under which ecosystem users operate; (iii) identify path-dependency in the institutional arrangements that shape future choices that ecosystem services will face; and (iv) detect drivers related to the sustainable provision of ES.

This Special Section draws to an end with a focus on urban ecosystems opening up the field which has traditionally been associated with natural and rural systems. Urban green spaces are able to provide bundles of regulating and cultural ES that contribute substantially to the welfare of urban dwellers. Hence, in a world in which $66 \%$ of the human population will live in cities by 2050 (PRB, 2014), special attention should be paid to the urban spaces' ability to provide ES. In the seventh paper of this Special Section, Stessens and collaborators present a novel approach to evaluate the accessibility and quality of urban green spaces. By combining surveys and spatial analysis, the authors unravel how the citizens of Brussels (Belgium) perceive and make use of the city greens. We believe that the approach presented in this paper will have a substantial positive impact on the elaboration of current urban planning actions.

A major issue in urban ecosystems, however, is the quality of the air. Poor air quality levels are associated to severe health problems, which are expensive to treat and, alas, are common in the vast majority of cities across the world (WHO, 2016). Urban green spaces have been acknowledged as effective air pollution filters (Räsänen et al., 2013). Trees, in particular, are able to absorb $\mathrm{CO}_{2}$ and release $\mathrm{O}_{2}$ to the urban atmosphere, as well as they can trap in their canopies suspended particles from the urban atmosphere. Yet, tools assisting the implementation of specific measures to improve the quality of the air in urban spaces are still lacking. In the last contribution to this Special Section, Salata and collaborators present a tool to map and model how urban green areas can contribute to a cleaner urban atmosphere by filtering the air. The tool presented by these authors can noticeably contribute to a 
better assessment of the ES embedded within cities and, as the rest of the contributions presented in this Special Section, to the design of effective, and sustainable, environmental management strategies.

Overall, the eight contributions in this Special Section showcase pragmatic approaches to deal with ES bundles, trade-offs, and synergies. These will hopefully lead to more comprehensive studies focusing on ES interactions within multifunctional ecosystems: from the identification and quantification of ES bundles, to the interpretation of management strategies able to ameliorate tradeoffs; from the detection of ES trade-offs, to the analysis of ES perceptions and conflicts. Yet, the task of dealing with ES relationships is nontrivial and, in many cases, it is site-specific. Future work will need to be reproducible under multiple environmental contexts and to tackle the dynamic nature of multifunctional ecosystems in order to ensure more resilient human societies in a continuously changing environment.

\section{Acknowledgments}

We are thankful to all the authors who contributed to this Special Section. Our sincere appreciation to the constant assistance from the Editor-in-Chief, Leon Braat, and the ECOSER team. Special thanks to the $5^{\text {th }}$ EcoSummit Organising Committee for giving us the opportunity to celebrate the session that gave birth to this special section. The authors acknowledge the financial support from the BEAM Research Centre at Glasgow Caledonian University. The work of the authors and Managing-GuestEditor (A. Gonzalez-Ollauri) was partly funded by the Erasmus+ project ECOMED (575796-EPPEPPKA2-KA; www.ecomedbio.org).

\section{References}

Bennett, E.M., Peterson, G.D., Gordon, L.J., 2009. Understanding relationships among multiple ecosystem services. Ecology Letters, 12, 1394-1404

Braat, L. and R. de Groot, 2012. The ecosystem services agenda: bridging the worlds of natural science and economics, conservation and development, and public and private policy. Ecosystem Services 1:415

China Council for International Cooperation on Environment and Development (CCICED), 2010. Annual General Meeting - Ecosystem Service and Management Strategy in China. http://www.cciced.net/cciceden/POLICY/rr/prr/2010/201205/P020160810466182396989.pdf

Daw, T., Brown, K., Rosendo, S., Pomeroy, R., 2011. Applying the ecosystem services concept to poverty alleviation: the need to disaggregate human well-being. Environmental Conservation, 38 (4), 370-379

de Groot, R.S., Alkemade, R., Braat, L., Hein, L., Willemen, L., 2010. Challenges in integrating the concept of ecosystem services and values in landscape planning, management and decision making. Ecological Complexity, 7, 260-272

Deng, X., Li, Z., Gibson, J., 2016. A review on trade-off analysis of ecosystem services for sustainable land-use management. J. Geogr. Sci., 26 (7), 953-968

Dillard, G., 1967. A moving window detector for binary integration. IEEE Transactions on Information Theory, 13 (1), 2-6 
Gonzalez-Ollauri, A. and Mickovski, S.B., 2017. Shallow landslides as drivers for slope ecosystems evolution and biophysical diversity. Landslides, 14(5), 1699-1714

Hein, L., van Koppen, C.S.A (Kris), van Ierland, E.C., Leidekker, J., 2016. Temporal scales, ecosystem dynamics, stakeholders and valuation of ecosystem services. Ecosystem Services, 21, 109-119

Howe, C., Suich, H., Vira, B., Mace, G.M., 2014. Creating win-wins from trade-offs? Ecosystem services for human well-being: A meta-analysis of ecosystem service trade-offs and synergies in the real world. Global Environmental Change, 28, 263-275

Koch, E.W., Barbier, E.B., Silliman, B.R., Reed, D.J., Perillo, G.M.E., Hacker, S.D., Granek, E.F., Primavera, J.H., Muthiga, N., Polasky, S., Halpern, B.S., Kennedy, C.J., Kappel, C.V., Wolanski, E., 2009. Non-linearity in ecosystem services: temporal and spatial variability in coastal protection. Front. Ecol. Environ., 7(1), 29-37

Kohonen, T., 1998. The self-organizing map. Neurocomputing, 21(1-3), 1-6

Werner, S. R., Spurgeon, J.P.G., Isaksen, G.H.C., Smith, J.P., Springer, N.K., Gettleson, D.A., N'Guessan, L., Dupont, J.M., 2014. Rapid prioritization of marine ecosystem services and ecosystem indicators. Marine Policy, 50, 178-189

Mouchet, M.A., Paracchini, M.L., Schulp, C.J.E., Stürck, J., Verkerk, P.J., Verburg, P.H., Lavorel, S., 2017. Bundles of ecosystem (dis)services and multifunctionality across European landscapes. Ecological Indicators, 73, 23-28

Mouchet, M.A., Lamarque, P., Martin-Lopez, B., Crouzat, E., Gos, P., Byczek, C., Lavorel, S., 2014. An interdisciplinary methodological guide for quantifying associations between ecosystem services. Global Environmental Change, 28, 298-308

Norton, L., Greene, S., Scholefield, P., Dunbar, M., 2016. The importance of scale in the development of ecosystem service indicators? Ecological Indicators, 61, 130-140

Population Reference Bureau (PRB), 2014. World Population Data Sheet. Available via: http://www.prb.org/pdf14/2014-world-population-data-sheet_eng.pdf

Räsänen, J.V., Holopainen, T., Joutsensaari, J., Ndam, C., Pasanen, P., Rinnan, A., Kivimäenpää, M., 2013. Effects of species-specific leaf characteristics and reduced wáter avaialbility on fine particle capture efficiency of trees. Environmental Pollution, 183, 64-70

Thompson, P.L. and Gonzalez, A., 2016. Ecosystem multifunctionality in metacommunities. Ecology, 97 (10) 2867-2879

Turkelboom, F., Thoonen, M., Jacobs, S., Garcia-Llorente, M., Martin-Lopez, B., Berry, P., 2016. Ecosystem services trade-offs and synergies. In: Potschin, M. and Jax, K. (eds): OpenNESS Ecosystem Services Reference Book. EC FP7 Grant Agreement no. 308428. Available via: http://www.openness-project.eu/library/reference-book

World Health Organisation (WHO), 2016. Fact sheet - Ambient (outdoor) air quality and health. Retrieved on 13/09/2017, http://www.who.int/mediacentre/factsheets/fs313/en/ 